\title{
Persistent Müllerian Duct Syndrome with Transverse Testicular Ectopia: A Novel Anti-Müllerian Hormone Receptor Mutation
}

\author{
Özlem Korkmaz ${ }^{1}$, Samim Özen ${ }^{1}$, Nurhan Özcan ${ }^{1}$, Petek Bayındır², Sait Şen ${ }^{3}$, Hüseyin Onay4, Damla Gökşen ${ }^{1}$, Ali Avanoğlu ${ }^{5}$, \\ Ferda Özkınay4, Şükran Darcan ${ }^{1}$
}

${ }^{1}$ Ege University Faculty of Medicine, Department of Pediatric Endocrinology, Izmir, Turkey

${ }^{2}$ Ege University Faculty of Medicine, Department of Radiology, Izmir, Turkey

${ }^{3}$ Ege University Faculty of Medicine, Department of Pathology, Izmir, Turkey

${ }^{4}$ Ege University Faculty of Medicine, Department of Genetics, Izmir, Turkey

${ }^{5}$ Ege University Faculty of Medicine, Department of Pediatric Surgery, Izmir, Turkey

\section{What is already known on this topic?}

Persistent Müllerian duct syndrome (PMDS) is a disorder of sexual differentiation characterised by the persistence of Müllerian derivatives in males with an XY karyotype and normal virilization. PMDS are caused by mutations in the anti-Müllerian hormone gene, which lead to defects in its secretion or activity, or to mutations in the gene for the type II receptor for anti-Müllerian hormone, which results in a clinical picture of hormonal resistance.

\section{What this study adds?}

We report a previously undescribed homozygous c.24G > A (p.W8X) mutation determined at AMHR2 gene analysis.

\begin{abstract}
Persistent Müllerian duct syndrome is the result of either anti-Müllerian hormone (AMH) deficiency or AMH receptor resistance. A long tubular structure was palpated during the physical examination of a 13-month-old male patient who had presented with bilateral undescended testes. At physical examination, the testes were not palpable. The patient's karyotype was XY, SRY (+), and his AMH level was $22 \mathrm{ng} / \mathrm{mol}$. Structures suggestive of ovaries, a uterus, and fallopian tubes were observed during the laparoscopic examination of the ectopic testis. AMHR2 gene sequence analysis performed with a preliminary diagnosis of AMH receptor resistance revealed a previously unreported homozygous c.24G > A (p.W8X) mutation. The patient was assessed as a case of AMH receptor resistance. Orchiopexy was performed.
\end{abstract}

Keywords: Undescended testis, anti-Müllerian hormone receptor mutation, anti-Müllerian hormone receptor resistance

\section{Introduction}

Persistent Müllerian duct syndrome (PMDS) is a rare disorder of 46,XY sex development. It occurs as a result of anti-Müllerian hormone (AMH) deficiency or $\mathrm{AMH}$ receptor resistance, conditions which arise due to mutations in the AMH gene or the AMH type 2 receptor (AMHR2) gene. In these patients, the external genital structure is that of a normal virilized male, while fallopian tubes and a uterus are observed in the internal genital structure $(1,2)$. Here, we report a case of PMDS in a 13-month-old male presenting with bilateral cryptorchidism and a novel homozygous mutation in the AMHR2 gene.

\section{Case Report}

A 13-month-old male presented to the pediatric surgery department with a complaint of bilateral undescended 
testis. A long, tubular structure (testis?) was palpated within the canal. Ultrasonography revealed absence of a testicular structure in the left inguinal canal or scrotum. On the right side, two structures measuring $12 \times 8 \mathrm{~mm}$ and $11 \times 7 \mathrm{~mm}$ and thought to be testes were observed in the proximal and middle parts of the inguinal canal. These findings were interpreted as transverse testicular ectopia on the right. During laparoscopic examination of the ectopic testis, tissues suggestive of a uterus, fallopian structures, and ovaries were observed inside the abdomen. Gonad biopsy was performed and the patient was referred to the pediatric endocrinology department with a preliminary diagnosis of sexual development disorder. At physical examination, weight was $10.2 \mathrm{~kg}$ [standard deviation score (SDS): -1.06] and height was $81 \mathrm{~cm}$ (SDS: -0.39). Blood pressure was 98/60 $\mathrm{mm} / \mathrm{Hg}$, Quickly score 2. The testes were not palpable and the phallus was $3.5 \mathrm{~cm}$ in length. The mother and father were first-degree relatives. Karyotype analysis revealed a XY, SRY (+) karyotype. Serum follicle-stimulating hormone level was $0.44 \mathrm{mIU} / \mathrm{L}(0.26-3 \mathrm{mIU} / \mathrm{L})$, luteinizing hormone was $0.27 \mathrm{mIU} / \mathrm{L}(0.02-0.3 \mathrm{mIU} / \mathrm{L})$, free testosterone 0.3 $\mathrm{pg} / \mathrm{mL}(0.15-0.6 \mathrm{pg} / \mathrm{mL})$, total testosterone $0.1 \mathrm{ng} / \mathrm{dL}(0.2-$ $1.3 \mathrm{ng} / \mathrm{dL}), \mathrm{E}_{2}<20 \mathrm{ng} / \mathrm{mL}(<15 \mathrm{ng} / \mathrm{mL})$, and $\mathrm{AMH}>22$ $\mathrm{ng} / \mathrm{mL}$ (4.9-264.5 ng/mL). Immature seminiferous tubular structures were observed in gonad biopsy specimens sent from the pediatric surgery department. AMHR2 gene sequence analysis performed with a preliminary diagnosis of $\mathrm{AMH}$ receptor resistance revealed a previously undescribed homozygous c.24G > A (p.W8X) mutation. The parents had the same mutation in heterozygous form. The patient was evaluated as a case of AMH receptor resistance and presented to our "Sex Development Disorders Council". Upon their decision, orchiopexy was performed.

\section{Discussion}

AMH is secreted from immature Sertoli cells in males and from ovarian granulosa cells in females and is responsible for the regression of the Müllerian ducts in the male fetus. The clinical picture that appears in the 46,XY genotype in AMH synthesis and effect deficiency is known as PMDS. This occurs as a result of mutations in the $A M H$ gene or in the AMHR2 gene. Serum AMH levels are low or undetectable in $A M H$ gene mutations, while they are normal or elevated in $A M H R 2$ gene mutations $(1,2)$.

Most cases of PMDS are diagnosed following a virilized XY patient presenting with bilateral or unilateral undescended testis or inguinal hernia. Three anatomic variants of PMDS have been described. In group 1 , bilateral testicles are located intraabdominally. In group 2 , one testis is located in a hernia sac or along with the Müllerian structures (hernial uterus inguinalis). In group 3 , both testes are found in the same hernia sac, along with uterus and tubes (crossed or transverse testicular ectopia) $(3,4)$. Given that the genotype of AMH and AMHR2 is not related to the phenotypes, the phenotype of our index case was consistent with group $3(5,6)$. Our patient presented to the Pediatric Surgery Department with a complaint of bilateral undescended testes and was referred to us when female internal genital structures were observed at laparoscopy. It has been reported that the undescended testes in PMDS may undergo malignant transformation. The prevalence of germ cell tumors such as seminoma, most commonly, as well as embryonal carcinoma, yolk sac tumor and, more rarely, clear cell adenocarcinoma in such patients varies from $15-40 \%$, a frequency no higher than that reported for abdominal testes in general $(7,8)$. Orchiopexy is therefore recommended as early as possible in these cases (9). In our case, too, orchiopexy was performed on both testes seen on the same side inside the abdomen, and both right and left were enabled to descend into the scrotum.

AMH is a member of the TGF-beta family. In males, serum levels of AMH remain high until 2 years of age and persist in measurable levels until puberty, before decreasing to undetectable levels at puberty $(10,11)$. Low or undetectable AMH levels in cases with PMDS indicate AMH mutation, whereas high $\mathrm{AMH}$ levels may indicate mutations in the AMHR2 gene (12). The $A M H$ gene is located on the short arm of the $1^{\text {th }}$ chromosome and was first cloned in 1986 by Cate et al (13). It consists of five exons and is $2.8 \mathrm{kbp}$ in length. PMDS exhibits an autosomal recessive pattern. Mutation in the $A M H$ gene or $A M H R 2$ gene has been reported in $84 \%$ of cases. AMHR2 gene mutations are located in the long arm $13.13(12 q .13 .13)$ region of the $12^{\text {th }}$ chromosome. AMHR2 contains 11 exons and more than 27 mutations have already been described in this gene $(14,15)$. The AMHR2 gene contains four intronic polymorphisms, located in t276a intron 1, c1280t intron 3, c1827t intron 5, and a6503g intron 10 (16). In a study of 32 families with PMDS, Imbeaud et al (17) determined mutations in the $A M H$ gene in 16 families and in the AMHR2 gene in the other 16. Deletion 27-bp in size was observed in the $10^{\text {th }}$ exon in 10 of the 16 patients with mutation in the $A M H H 2$ gene. This mutation has been reported as the cause of $25 \%$ of cases of PMDS (17). AMH receptor resistance was primarily considered in our case due to AMH level. At mutation analysis, a previously undefined homozygous c.24G > A (p.W8X) mutation was determined at $A M H R 2$ gene analysis. Mutation screening revealed that the mother and father bore the same mutation in heterozygous form. 
In conclusion, in cases with bilateral cryptorchidism, the clinicians should be aware of the possibility of PMDS. The condition should be considered when persistent Müllerian structures are observed, particularly in virilized males with a normal external genital structure.

\section{Ethics}

Informed Consent: After getting informed consent from the parents, genetic analysis was performed.

Peer-review: Externally peer-reviewed.

\section{Authorship Contributions}

Concept: Samim Özen, Şükran Darcan, Design: Özlem Korkmaz, Samim Özen, Data Collection and Processing: Özlem Korkmaz, Analysis and Interpretation: Özlem Korkmaz, Samim Özen, Nurhan Özcan, Petek Bayındır, Sait Şen, Hüseyin Onay, Damla Gökşen, Ali Avanoğlu, Ferda Özkınay, Şükran Darcan, Literature Research: Özlem Korkmaz, Writing: Özlem Korkmaz, Samim Özen.

Financial Disclosure: The authors declared that this study received no financial support.

\section{References}

1. Josso N, Belville C, di Clemente N, Picard JY. AMH and AMH receptor defects in persistent Müllerian duct syndrome. Hum Reprod Update 2005;11:351-356. Epub 2005 May 5

2. Guerrier D, Tran D, Vanderwinden JM, Hideux S, Van Outryve L, Legeai L, Bouchard M, Van Vliet G, De Laet MH, Picard JY, Kahn A, Josso N. The persistent Müllerian duct syndrome: a molecular approach. J Clin Endocrinol Metab 1989;68:46-52.

3. El-Gohary MA. Laparoscopic management of persistent müllerian duct syndrome. Pediatr Surg Int 2003;19:533-536. Epub 2003 Sep 9

4. Manjunath BG, Shenoy VG, Raj P. Persistent müllerian duct syndrome: How to deal with the müllerian duct remnants - a review. Indian J Surg 2010;72:16-19. Epub 2010 Feb 5

5. Van der Zwan YG, Brüggenwirth HT, Drop SL, Wolffenbuttel KP, Madern GC, Looijenga LH, Visser JA. A novel AMH missense mutation in a patient with persistent Müllerian duct syndrome. Sex Dev 2012;6:279283. Epub 2012 Jul 11
6. Mazen I, Abdel Hamid MS, El-Gammal M, Aref A, Amr K. AMH gene mutations in two Egyptian families with persistent mullerian duct syndrome. Sex Dev 2011;5:277-280. Epub 2011 Dec 20

7. Cools M, Drop SL, Wolffenbuttel KP, Oosterhuis JW, Looijenga LH. Germ cell tumors in the intersex gonad: old paths, new directions, moving frontiers. Endocr Rev 2006;27:468-484. Epub 2006 May 30

8. Bucci S, Liguori G, Buttazzi L, Bussani R, Trombetta C. Bilateral testicular carcinoma in patient with the persistent müllerian duct syndrome. J Urol 2002;167:1790.

9. Berkmen F. Persistent müllerian duct syndrome with or without transverse testicular ectopia and testis tumours. Br J Urol 1997;79:122126.

10. Shamim M. Persistent Mullerian duct syndrome with transverse testicular ectopia presenting in an irreducible recurrent inguinal hernia. J Pak Med Assoc 2007;57:421-423.

11. Bergada I, Milani C, Bedecarras P, Andreone L, Ropelato MG, Gottlieb S, Bergadá C, Campo S, Rey RA. Time course of the serum gonadotropin surge, inhibins, and anti-Müllerian hormone in normal newborn males during the first month of life. J Clin Endocrinol Metab 2006;91:40924098. Epub 2006 Jul 18

12. Josso N, Rey R, Picard JY. Testicular anti-Müllerian hormone: clinical applications in DSD. Semin Reprod Med 2012;30:364-373. Epub 2012 Oct 8

13. Cate RL, Mattaliano RJ, Hession C, Tizard R, Farber NM, Cheung A, Ninfa EG, Frey AZ, Gash DJ, Chow EP, Fisher R.A., Bertonis J.M., Torres G., Wallner B.P., Ramachandran K.L., Ragin R.C., Manganaro T.F., MacLaughlin D.T., Donahoe P.K. Isolation of the bovine and human genes for Müllerian inhibiting substance and expression of the human gene in animal cells. Cell 1986;45:685-698.

14. Abduljabbar M, Taheini K, Picard JY, Cate RL, Josso N. Mutations of the AMH type II receptor in two extended families with persistent Müllerian duct syndrome: lack of phenotype/genotype correlation. Horm Res Paediatr 2012;77:291-297. Epub 2012 May 11

15. Belville C, Marechal JD, Pennetier S, Carmillo P, Masgrau L, MessikaZeitoun L, Galey J, Machado G, Treton D, Gonzalès J, Picard JY, Josso $\mathrm{N}$, Cate RL, di Clemente N. Natural mutations of the anti-Müllerian hormone type II receptor found in persistent Müllerian duct syndrome affect ligand binding, signal transduction and cellular transport. Hum Mol Genet 2009;18:3002-3013. Epub 2009 May 20

16. di Clemente N, Belville C. Anti-Müllerian hormone receptor defect. Best Pract Res Clin Endocrinol Metab 2006;20:599-610.

17. Imbeaud S, Belville C, Messika-Zeitoun L, Rey R, di Clemente N, Josso N, Picard JY. A 27 base-pair deletion of the anti-Müllerian type Il receptor gene is the most common cause of the persistent Müllerian duct syndrome. Hum Mol Genet 1996;5:1269-1277. 